\title{
Junior Secondary School Students' Ideas of Chemical Change
}

\author{
Azure, J. A. \\ Department of Science Education, University of Education, Winneba, Ghana.
}

\begin{abstract}
The study examined Junior Secondary School students' ideas about chemical change. The study also focused on the identification of misconceptions that students might harbour on this concept. It also sought to examine the implications of such ideas for teaching and learning of science at the basic level. Students selected for the study were from well-established and poorly-established schools in the Awutu-Efutu-Senya District in the Central Region of Ghana. In all 464 students were randomly sampled for the study. Instruments used in the study consisted of a test and an interview schedule. The t-test statistic for independent sample was used to test the null hypothesis of the research question. The study found no significant differences between students from both well-endowed and poorly-endowed schools on the ideas they held about chemical change. Students from both well-established and poorly established schools showed common misconceptions about chemical change. Analysis of test and interview revealed the following misconceptions (i) that the burning of a candle is a physical change and (ii) the blackening of a glass rod is due to vapour from the flame.
\end{abstract}

Keywords: chemical change, basic science,

\section{Introduction}

Teachers can be astonished to learn that despite their best efforts, students do not grasp the fundamental ideas covered in class. Even some of the best students give right answers by reproducing what they have memorized. When questioned more closely, these students reveal their failure to understand fully the underlying concepts. Mazu (1996) reports that students in their physics class memorized equations and problem-solving skills but performed poorly on test of conceptual understanding.

The child even before he/she comes to school has certain ideas of the world as a result of his/her interaction with the environment. These are the child's preconceptions, and they affect his/her understanding of concepts taught in class. Ruseel (1956) states that the soundness of a child's concepts of things are the best measure of his probable success in school learning because meaning is fundamental to such success. In many cases, students have developed partially correct ideas that can be used as the foundation for further learning.

\section{Children's conception of chemical change}

Abraham, Williamson \& Westbrook (1994) conducted research on children's conceptions of chemical change using a burning candle and a glass rod for their investigation. The rod was placed through the flame of the burning candle and a black film deposited on the rod. Children were asked to explain the source of the black film on the rod. They concluded that misconceptions concerning chemical change run through majority of the students. The most common misconception was that, burning of the candle was a physical change because the candle had undergone a phase change or was the same substance. Another major misconception reported was the notion that the black material from the rod came from the combustion of the wick. $4 \%$ junior high school, $10 \%$ high school and $25 \%$ college students held this misconception. These students indicated that the wick was being burned, not the wax.

In a separate study, Johnson (2000) discovered that his pupils had difficulties in explaining transformation that occur in chemical reactions. Eskilsson(2003) interviewed 40 junior high school pupils on chemical reactions during a two-year longitudinal study on mixing of everyday 
substances; and stated that pupils of the age group 11-14 years had difficulty understanding simple chemical reactions. Very few students interviewed in that study showed that it was possible to use every day material and situations when teaching and discussing about how substances interact; or how new substances were formed as a result of chemical interactions in the early age in school (Eskilsson, 2003).

Valanides (2000) in a study conducted into the understanding of distillation by student teachers practicing in primary schools reported that some of the students saw boiling to be chemical change where gases of oxygen and hydrogen are produced. This was an indication of their inability to understand boiling as physical change. When alcohol solution was considered, 25\% of them insisted that the distillate would be t5he same mixture of water and alcohol. Fifteen percent of them believed that when mixing water and alcohol, a chemical change occurs and a totally new liquid is formed. Some of them expressed an additive rather than an interactive conception of chemical change (Valanides, 2000).

Most students were not sure whether chemical change occurs during the process of brewing tea; but they felt that the colour itself changed the nature of the liquid, which is similar but different from water. Students believed that the colour of red wine was related to the nature of the liquid that is found in red grapes. They stated that it is impossible to produce red wine from white grapes. None of them mentioned alcoholic fermentation, which is a chemical change. Furthermore, students believed that the colour of coke "was chemically added" in factories, but "once a liquid is coloured, a totally new liquid was formed, and it is impossible to obtain a colourless liquid by distilling it". Some of the students $(3 \%)$ thought that a chemical change occurs when salt is dissolved, sugar $(3 \%)$, or alcohol $(15 \%)$ in water, and that the initial materials do not exist any more and a new material with its own properties will be formed.

Valanides (2000) concluded that the students face difficulties in understanding the essential changes during chemical transformations of matter involve the breaking apart andd recombination of molecule and therefore, are unable to differentiate chemical from physical transformation where the structure of the molecule is unaffected. Martin de Pozo and Porlyn (2001) reported on Spanish prospective teachers' idea about teaching the concept of chemical change to their pupils and concluded that only half (12 out of 24) of the students explicitly formulated the concept of chemical change they expected their 13-14 year pupils to know. They stated specifically that they expected their children to:

(i) realise that in physical changes the nature of the substance does not vary (although its appearance does) while in chemical changes the nature does, and (ii) the children will have to come to the conclusion that the new substance which has been formed has characteristics which are different from initial substance. These formulation were at the macroscopic level, in terms of change in identify of initial substances rather than of conservation (of the elements), in contrast with physical changes.

\section{The purpose of the study}

The first purpose of this study was to investigate junior secondary school students' preconceptions and misconceptions about chemical change so that teachers may design instruction to address misunderstandings thereby ensuring scientific understandings of important concepts on chemical reactions. Another objective of the investigation was to determine the differences (if any) between students of both the well-established and poorly established schools' preconceptions and misconceptions about chemical change stemming from differences in school learning environments. In the area of science misconceptions, will the types of misconceptions or their frequency differ between the two groups? This question will be investigated as children's ideas from two groups of elementary children in the same school district are compared. 


\section{Significance of the study}

A study of pupils' misconceptions about chemical change will help teachers attend to these ideas during instruction. Although, as students mature and gain deeper understandings of chemical reactions and simple physical relationships, some misunderstandings will be clarified, other ideas will remain unchanged unless directly addressed. Children soon grow to become responsible adults and clear understandings of chemical changes due to chemical reactions will lead to informed decisions, affecting our global community and the environment in a positive way.

Also as Henriques (2002) states, most teachers are far too busy to gather misconception data from their students or from research. If a list of topic related misconceptions were made available to teachers, they could review the list when planning instruction so that students' ideas could be included. Lists like those in this article can be provided to preservice and inservice teachers, as well as methods instructors, to challenge misconceptions junior secondary school students still hold and to help teachers get prepared for pupils.

\section{Methodology}

\section{Sampling and sample}

The Awutu-Efutu-Senya District is officially divided into six educational circuits. These are Winneba East, Winneba West, Senya, Awutu, Bawjiase and Bontrase circuits. All the schools in the six circuits were grouped into well-established and poorly-established. This was done with the help of two inspectors of schools at the District Education Office, Winneba prior to the selection process.

The criteria used for this categorisation included, for well-established schools, the presence of good library, adequate text books and exercise books for each student, one student to one writing desk, teachers' common room, qualified teachers for all subjects taught. The absence of these things mentioned in any school qualified such a school to be tagged poor. Some of the poor schools had no classrooms and their students had to sit under shade of big trees. Twelve schools were used for the main study. Balloting was used in a circuit where there was more than one well-established or poorly established schools to get one of such schools for participation in the study.

The stratified random sampling method was used to select the sample of students. This permitted the investigator to select from subgroups of the population. Secondly, it ensured that each member of the population had the same probability of being selected. The different strata were well-established and poorly established schools, JSS 2 and JSS 3 students. With the JSS system each stage is a stratum. Only two of the strata (JSS 2 \& JSS3) were used for the study. All JSS 2 and JSS 3 students in the district formed the accessible population. Out of these 12 schools, six were classified as well-established and the other six as poorly-established. A table of random numbers was then used to select the students that took part in the study. A sample of 20 students was selected in each form, thus a total of 40 students were chosen in each school to take part in the exercise. The overall sample size that was used in this study was 464 made up of 235 students from well-established and another 229 students from poorly-established JSS schools in district. A total of 96 students who were randomly selected from the participants took part in an interview. The 96 interviewees were made up of 48 JSS 2 and 48 JSS 3 students, comprising of four students from each participating school.

\section{The instruments}

Many of the international, well-validated instruments used to study understandings of science concepts have weakness (Leaderman, Wade \& Bell, 1998). Questions are often closed and use 
multiple-choice format, which often limit the information that can be obtained from participants. This is avoided in the current study by using two structured instruments. One was a test and the other an interview schedule. The interview schedule was added to correct the inherent weaknesses of using only test items. The interview will help in triangulation of the results of the study. Also the open-ended item permitted respondents to express their ideas clearer. A pilot study was conducted using 120 students from 4 schools in the Gomoa District in the Central region. The instrument that was used for the pilot study was modified for the main study.

The test was developed and administered to the chosen sample consisted of 11 items in total, with 10 closed-ended items under Section A and one short open-ended item under Section B. the open-ended question measured the students' understanding of chemical change and required the students to explain the source of the black substance deposited on the glass rod held in the candle flame. The interview guide consisted of the item in Section B of the test. It measured pupils' understanding of chemical change based on the experimental activity they performed. The purpose was to compare students' verbal responses in the interview with their written texts that helps in triangulation.

\section{Validity and reliability of the instruments}

The method for establishing or evaluating the reasonableness of test content is usually by expert judgement (Shepard, 1997). The test items and the interview guide were before use, submitted to a three-man panel from the Faculty of Science Education. Two of them were from the Department of Science Education; one other expert was from the Department of mathematics Education. The three experts validated the instruments for content, and face validity. The objectives of the content were made known to experts this helped them in the validation process. Their suggestions were used to modify the testing instrument and interview schedule before they were administered to the pilot sample. The resulting data from the pilot study was used to determine the reliability of the instrument.

The estimate of the internal consistency of the achievement test was determined through the application of the Kuder-Richardson 21(KR-21) formula and Cronbach alpha coefficient. Using Kuder-Richardson 21(KR-21) formula, a reliability coefficient of 0.84 was established for the multiple-choice set of items (SectionA) of the test. Using Cronbach (1951) formula the reliability of Section B was obtained to be 0.78 . These two internal consistency coefficients were evaluated by employing the SPSS computer programme.

\section{Administration of the instruments}

The data collection process was divided into two parts. The first part involved the administration of the test and the second part was the interview. Students were allowed 60 minutes to give their responses to the test items. The test was administered as a written task. The sampling and administration of the test and face-to-face individual interviews were carried out on the same day for any school visited. This prevented losing some participants. This ensured $100 \%$ return of the responses. A whole day of was spent in any school visited; sometimes extra time was spent out of official school hours. The interview time per students was between 15 to 20 minutes. Interview results were hand-recorded in a small notebook.

\section{Analysis of data}

The t-test statistic for independent samples was used to test the null hypothesis of research question. The null hypothesis states that "there is no significant difference in the ideas held by students of well-established and those of poorly-established JSS schools with respect to 
chemical change". Scores were tabulated and converted into percentages to analyse the research question. The scoring for the multiple-choice items was on the basis of one mark for a correct response and a zero score for an incorrect or no response. The data from the test were coded and quantified, and then recorded on data summary sheets, following the format required by the Statistical Package for the Social Sciences (SPSS), computer software for windows described by Bryman \& Crammer (1990). The data were subsequently entered into the computer and the SPSS was used in the statistical analysis.

A t-test analysis at a significant level of 0.05 was therefore performed to test the independence of the variable type of school against performance of students' on the concept of chemical change. For scores of Section A were added to that of Section B for computing the t-score.

\section{Results}

\section{Students' performance on chemical change}

The research question, "do students of well-established and poorly-established Junior Secondary Schools have significantly different ideas about chemical change", was answered by using data results of items under Section A and one question under Section B of the test.

Table 1 Type of school and distribution of percentage of students who scored in respective items 1-10 for Section $A$ of the test on chemical change

\begin{tabular}{lllllllllll}
\hline Item No & 1 & 2 & 3 & 4 & 5 & 6 & 7 & 8 & 9 & 10 \\
\hline Well-endowed school & 50 & 44 & 58 & 43 & 47 & 47 & 32 & 41 & 50 & 18 \\
Poorly-endowed school & 34 & 31 & 36 & 33 & 33 & 27 & 29 & 17 & 43 & 12 \\
\hline
\end{tabular}

See Appendix B for items numbered 1-10 on chemical change.

The data collected on the study showed that overwhelming majority of the students had one or more on misconceptions incorrect. Fifty-eight percentage of students from well-established schools had item 3 correct whilst only $36 \%$ of students from the poorly-established schools had that item correct. Again $50 \%$ of the students of well-established schools had items 1 and 9 correct. These were only the items in which students faired well. Students of both wellestablished and poorly-established schools performed poorly on the concept of chemical change.

Table 2 Type of students' performance on chemical change

\begin{tabular}{llllllll}
\hline Type of school & $\mathrm{n}$ & $\mathrm{M}$ & $\mathrm{S}^{2}$ & $\mathrm{SD}$ & $\mathrm{df}$ & $\mathrm{t}($ cal. $)$ & $\mathrm{p}$-value \\
\hline Well-endowed school & 235 & 21.8 & 2.31 & 1.52 & & & \\
Poorly-endowed school & 229 & 21.5 & 2.62 & 1.62 & 462 & 0.21 & $\mathrm{P}<05$ \\
\hline
\end{tabular}

Theoretical $\leq 1.96$ p $>.05, n=$ sample size, $M=$ mean performance, $S^{2}=$ variance, $S D=$ standard deviation, $\mathrm{df}=$ degree of freedom and $\mathrm{t}(\mathrm{cal})=$ calculated $\mathrm{t}$-value.

The performance of students in the test was very poor. Less than $50 \%$ of the 464 students gave correct interpretation of chemical change. The results in Table 2 showed a mean score of 21.8 for students of well-endowed schools and 21.5 for those in poorly-endowed schools. The difference in their means is 0.3. This suggests that students from well-endowed schools performed much better than their colleagues. None of the two groups obtained an average score of $50 \%$ on the test on chemical change, only a few students from either side showed sound understanding of chemical change. Only 15\% percent of students from well-endowed schools gave incorrect responses to all items on chemical change, whilst as much as $24 \%$ of their colleagues gave incorrect responses to the same items. A-test was performed to determine whether there was any a significant difference between the two groups in terms of the ideas that they hold on chemical change. The calculated t-value was $t(462) \mathrm{df}=0.21, \mathrm{p}<.05$ on assumed 
equality of variances (Popham, 1990). But the theoretical t-value from tables for $n_{1}+n_{2}=462$ is $\mathrm{t}_{0.25}=1.96$ (two tailed). The calculated $\mathrm{t}(462)=0.21$ fell in the region of non-rejection of the null hypothesis that there was no significant difference between the two groups of students in the ideas they have of chemical change at a significant level .05.

\section{Discussion}

Based on the environments of the two categories of students, it is quite surprising that the two groups have similar ideas about chemical change and that they hold no divergent ideas on the concept. Their mean performances and standard deviations are very close with suggests that the two groups have similar ideas and knowledge of this concept. The SPSS computed $t(462)=$ 0.21 is less than the theoretical value at $5 \%$ level significance. The slight differences in their means and standard deviations could be due to measurement errors. It was discovered that students from both sides hold certain misconceptions about chemical change.

The most common misconception found among students was that the burning candle was only physical change, because the candle has undergone a phase change. The source of this misconception could be the fact that one could see the wax in a different from during and after the burning process. This idea was noticed in both the written work and during interview. It was coincidental that about $42 \%$ of students from both categories of schools harboured the notion that only physical change occurs in a burning candle as revealed by Table 3 . This misconception might have arisen because students thought that at the end of the burning process one could still retrieve pieces of wax from the burnt candle. Similar (but not exact) ideas held by children of such an age group (15 to 18 years) were reported by Abraham et al. (1994). According to these authors, students indicated that it was the wick that was being burnt, not the wax, while others concentrated on the rod and said it as unchanged. Though $44 \%$ of students from poorly-established schools, during interview responded that a burning candle is an example of chemical change, further probing showed that only eight percent of them had the right notion of chemical change (see Table 3 ).

When students were asked to comment on what made a glass rod held over the flame of the burning candle to become darkened, varying and divergent views were expressed. The following words: smoke, heat, fire, flame, vapour, gas and air were identified from students' scripts as being what caused the blackening of glass rod. Two percent of the students from the poorly-endowed schools remained silent on the issue. Table 3 shows type of school and percentage distribution of students according the views they held on what caused the darkening of the rod that was passed through the flame of a burning candle.

Table 3 Type of school and percentage distribution of students based on their held notions of what caused the glass rod to darken

\begin{tabular}{lllllll}
\hline Type of school & Smoke & Heat & Fire/flame & Vapour & Gas/air & Silent \\
\hline Well-endowed school & 33.70 & 31.70 & 19.52 & 9.76 & 3.88 & 1.00 \\
Poorly-endowed school & 35.18 & 29.35 & 22.03 & 6.45 & 4.00 & 2.00 \\
\hline
\end{tabular}

NB: All numbers are in percentages (\%)

Many of the students held the view that smoke deposits on the glass rod caused the blackness. This idea was formed to be common among students from the two categories of schools. The results revealed that $33.70 \%$ of the students from the well-endowed schools said the cause was due to smoke whilst $35.18 \%$ of students from the other category of schools were of the same view. Other students had the misconception that it was heat $(29.35 \%$ of well-endowed and $31.70 \%$ of their counterparts); still others said it was fire and or lame, which made the glass rod to blacken. These misconceptions were seen to run through all grade levels and among students from both categories of schools.

The following two unedited statements were sampled from such students. 
"When the candle is cover by the glass rod the heat turn to wax and goes on top of the glass rod and black it".

"The black film on the rod is the vapour of candle flame' and the black film on the rod formed because there is no air passing between the flame and the rod".

Some students attributed the black substance on the glass rod to vapour from the candle. The percentage of students who held this was $6.45 \%$ and $9.76 \%$ for poorly-endowed and wellendowed schools respectively. The following written expression of a student of an endowed school declares his misconception about the concept. "The black film on the rod is the vapour of the candle flame, and the black film on the glass rod formed because there is no air passing between the flame and the rod".

Others too expressed the view that gas or air coming out from the flame of the candle caused the rod to blacken. Four percent and $3.88 \%$ of students from poorly-endowed and wellendowed schools respectively held such a notion. The statements made on his this view were however weak to actually tell whether they meant that the air carried soot, which could have been the particle that caused the blackening of the rod. The following expressions below are culled from such students.

"The source of the black film on the glass is the air coming out from flame" and "the black film on the glass rod is that there is carbon dioxide in the candle or rope of the candle and cause the rod to black". Such students hold the misconception that carbon dioxide gas is embedded in the candle. This misconception might have arisen due to formal taught knowledge that, when substances burn, carbon dioxide is produced, but which was not well understood by the students.

Similar naïve ideas held by students on chemical change were noticed by Abraham et al. (1994) and Arozona State University (2001). Some of the students (2\%) who reported that chemical change occur in a burning candle, had a misconception of the process itself. To them the process was a chemical change because the candle goes into liquid form.

The interview revealed how student's uncertain beliefs could be changed through verbal interaction with them. Students may mention that chemical change occur in a candle that is burning but that does not necessarily mean that they have sound knowledge of the process of chemical change. Further probing could reveal surprisingly, the wrong notions the students have of the concept. For instance, when students were asked during interview, what they thought the process of burning a candle could be, some quickly chemical change, various interpretations were given. Some of these ideas were culled unedited from their statements and are listed below in italics.
The process is chemical change because:
(i) You see the candle burning and all of it goes down.
(ii) When it is burning you cannot see the burning.
(iii) You cannot get the candle back again.
(iv) The candle is spoiled.
(v) It goes into liquid form or candle the candle melts.

The above examples illustrate how students might conceptualise taught science in terms of the frameworks of their existing conceptualisations and results in powerful conceptual outcomes. These predictions and explanations of students are not in conformity with formal science and sometimes are very difficult to break by traditional lecture methods. Table 4 gives the percentage distribution of students with varying ideas about chemical change in burning candle. Though $42 \%$ of students from the well-endowed schools alluded to the fact that burning of a candle is an example of chemical change, only $11 \%$ of them actually had sound knowledge of the concept. The remaining $31 \%$ though said the process was chemical, gave varying unscientific explanations of the concepts. Such a group has been classified as those with 
misconceptions of chemical change (cc*) in Table 4. a typical statement was "it is chemical because when it is burning you cannot see the burning". Only $8 \%$ out of a total of $44 \%$ of poorly-endowed school students who said that chemical change occurs in a burning candle had sound knowledge of chemical change.

Table 4 Type of school and distribution of students according to their held notions on the process of chemical change occurring in a burning candle

\begin{tabular}{llllll}
\hline Type of school & CC & CC* & PC & NI & Total \\
\hline Well-endowed school & 11 & 31 & 42 & 16 & 100 \\
Poorly-endowed school & 8 & 36 & 42 & 14 & 100 \\
\hline
\end{tabular}

Note: All numbers are in percentages (\%)

Where $\mathrm{CC} \rightarrow$ those who have sound knowledge of chemical change process.

$\mathrm{CC}^{*} \rightarrow$ percentage of those who respond 'chemical change' during interview but had misconception of chemical change process.

$\mathrm{PC} \rightarrow$ those who said the process is physical change.

NI $\rightarrow$ those who have no idea of the process occurring in a burning candle.

It was coincidental that about $42 \%$ of both well-endowed and poorly-endowed school students harbour the notion that physical change occurs in burning candle. This misconception might have arisen because students think that at the end of the burning process, one could still retrieve pieces of wax from the burnt candle. Some of them said it was physical change because the black substance deposited on the rod could easily be cleaned from it. Students might have concentrated on the rod itself and hence concluded that still be rod was still available the process was a physical one. The students indicated that it was the wick that was being burnt and not the wax; while others concentrated on the rod and said it was unchanged. Eight percent of poorly-endowed school students had the right notion that chemical change occurs in a burning candle though $44 \%$ of them during interview responded that a burning candle is example of chemical change.

\section{Conclusion}

The results have demonstrated that the concept of chemical change is one that holds both instructional and curricula significance, as described by Eskilsson (2003), Johnson (2000), Anderson (1990), Anderson \& Smith (1987) and by Hollon and Anderson (cited in Hess and Anderson, 1992). The misconceptions found in this study in this study on chemical change meet the requirements for instructional significance because (i) such misconceptions are believed by many students, (ii) they are held by deep conviction and cannot be easily abandoned, and (iii) they hold the promise of being change with proper instruction. The patterns in students' responses in the study demonstrate that this concept also hold curricular significance. To hold curricular significance the native concepts must involve concepts fundamental to the discipline.

Many of the explanation given by students to chemical changes, and phase changes due to burning are incompatible with atomic molecular theory, which pervades all of chemistry and part of biology and physics. The confusion over what kinds of explanations are acceptable for chemical change highlights a larger problem how students explain all scientific phenomena.

Analysis of interview indicated that were some students who had fair knowledge of chemical change but could not express not express such ideas in written form. This situation was the same for both groups of students. Though the sample of the study and the result could not represent the general situation in Ghana, the findings provide some clues on the differences that 
can exist between endowed and not-endowed schools outside the sampled area with respect to the three concepts studied.

\section{Recommendations}

In the light of the findings, the researcher recommends that JHS science teachers should make strenuous effort in confronting students' misconceptions it is a good strategy in class to make the child aware of his/her misconceptions and guide him/her to actively take part in criticising and revising the misconception. In addition, the researcher recommends the areas that follow for further investigations.

- Extending the study to all the ten regions of Ghana using a variety of school science content to identify commonalities and differences in an attempt to enable the generalizability of the findings.

- Universities concerned with pre-service teacher preparation carrying out research into science topics that teachers find difficult teaching at the JSS level; and include such topics in their undergraduate programmes for pre-service teachers.

- Researching into post-secondary teachers' understanding of basic science concepts for they form majority of the teachers who teach science at the JSS level in Ghana. Such a study should aim at setting up in-service training programmes to help improve their science teaching knowledge.

\section{References}

Abraham, M. R., Williamson, V. M. \& Westbrook, S. L. (1994). A cross-age study of the understanding of five chemistry concepts. Journal of Research in Science Teaching, 31(2), 147-165.

Anastasi, A. (1998). Psychological testing. New York: Macmillan

Anderson, B. (1990). Pupils' conceptions of matter and its transformation (age 12-13). Studies in Science Education, 18, 53-85.

Anderson, C. W., \& Smith, E. L. (1987). Teaching science. In: V. Richardson-Koehler (ed.), Educators' handbook: A research perspective, pp. 84-111. New York: Longman.

Arizona State University (2001). Students Preconceptions and Misconceptions in Chemistry.VisitedApril2002.

http://www.daisley.net/hellevator/misconceptions/misconceptions.pdf

Benjamin, A. (1981). The Helping Interview. Boston: Haughton Muffin.

Bryman, A. \& Crammer, D. (1990). Quantitative Data Analysis for Social Scientists. London: Routledge.

conceptions in science. In: D. L. Gabel (ed.). Handbook of research. New York: Macmillan.

Cronbach, L. J. (1951). Coefficient alpha and the internal structure of tests. Psychometrika, 16, 297-334.

Esilsson, O. (2003). Children's talking about chemical reactions. physc.u.unl/esera./pdf/237S.

Henriques, L., 2002, Children's ideas about weather: A review of the literature, School Science and Mathematics, v. 101, p. 202-215.

Hess, J. J. \& Anderson, C. W. (1992). Students' conceptions of chemical change. Journal of Research in Science Teaching, 29(3), 277-299. 
Johnson, P. (2000). Children's understanding of substances, part 1: recognising chemical change: international Journal of Science Education, 22(7), 719-737.

Kerlinger, F. N. (1979). Behavioural research. A conceptual approach. New York: Holt, Rinehart and Winston.

Klausmeire, J. H. (1958). Teaching in secondary school: A revision of principles and practices of secondary school teaching. New York: Harper \& Brothers.

Krnel, D., Waston, R., \& Glazar, D. (1998). Survey of research related to the development of the concept of matter. International Journal of Science Eduucation, 20(3), 257-289.

Lederman, N. G., Wade, P. \& Bell, R. L. (1998). Assessing understanding of the nature of science: A historical perspective. In:P McComas, W. F. (ed.). The nature of science in science education-rationales in strategies (pp. 331-350). Dordrecht; Kluwer Academic Publishers.

Marshall, J. C., \& Hales, L. W. (1972). Essentials of testing. Reading, Massachusetts: AddisonWesley Publishing Company.

Popham, W. J. (1990). Modern educational measurement (2ed.) Englewood Cliffs, NJ: Printice Haqll.

Russell, D. H. (1956). Children's thinking. New York: Holt, Rinehart \&Winston.

Shepard, L. A. (1997). The centrality of test use and consequences for test validity. Educational Measurement: Issues and Practice, 16(2), 5-24.

Wandersec, J. H., Mintzes, J. J., \& Novak, J. D. (1994). Research on alternative

Westbrook, S. L. \& Marek, E. A. (1992). A cross-age study of student understanding of the concept of homeostasis. Journal of Research in Science Teaching, 29(1), 51-61.

Za'rour, G. T. (1975). Science misconception among certain groups of students in the Lebanon. Journal of Research in Science Teaching, 12(7). 